\title{
A New Probe Into Translation Teaching From the Perspective of Context
}

\author{
MA Yanling \\ Beijing International Studies University, Beijing, China
}

\begin{abstract}
Translation, as a cross-linguistic and cross-cultural communication activity, is closely related to context, so context is an essential factor in translation teaching. In traditional translation teaching, students' contextual awareness is weak, and there are few translation practice opportunities for students. As a result, many students' translation level fails to meet the basic requirements of the market. This paper attempts to introduce the concepts and theories of context into translation teaching, and then to explore the reforms and attempts that need to be made in translation teaching after the combination of context and translation teaching. It also stresses that translation teachers are required to face new challenges and requirements coming from translation textbooks, teaching contents, and the creation of context, and to have a contextual perspective so as to achieve effective translation teaching.
\end{abstract}

Keywords: context, translation teaching, translation talents

\section{Introduction}

Translation teaching in college English has been a hot topic in academic circles in recent years. The study of translation teaching is also an important part of translation research. The translation teaching discussed in this paper mainly refers to the translation teaching of senior English majors.

Chinese college English translation teaching has always been considered as "teaching translation", that is, the teaching aimed at helping students improve their language ability but not translation skills. With the increasing demand for practical translators in the development of society, the traditional "teaching translation" cannot train qualified translators.

Context studies in recent years have shown that context is very important in translation teaching. Contextualized translation teaching has been recognized and applied to teaching practice by more and more scholars and teachers. This article intends to discuss "translation teaching” from the perspective of "context".

\section{Context and Translation}

The study of "context" is diversified, since the study of context is involved in philosophy, logic, anthropology, and linguistics. Context has been included in the field of translation studies since the 1980s, and has gradually become a hot topic in translation studies, which is of great significance to the study of translation. The concept of "context" was first explicitly put forward in 1923 by an anthropologist Malinowski. He believes that context can be divided into situational context and cultural context; the former refers to the objective environment directly related to language communication activities, and the latter refers to the whole cultural

MA Yanling, Master’s degree, lecturer, School of English Language, Beijing International Studies University, Beijing, China. 
background in which language communicators live (Malinowski, 1923). In the 1950s, Firth, the founder of London School, divided context into three levels: linguistic context, situational context, and cultural context, which laid the foundation for the further development of context theory (Firth, 1957). Halliday, a famous contemporary British linguist, systematically studied the context and divided the context into "linguistic context" and "non linguistic context", paying more attention to the relationship between language and society (Halliday, 1978). Since the 1960s, the study of context has attracted extensive attention in linguistic circles in China. Domestic scholars Hu Zhuanglin, Zhu Yongsheng, and Zhang Delu (1989) divide context into linguistic context, situational context, and cultural context. In 2003, Liu Miqing put forward the theory of context in translation, pointing out that the readability and acceptability of the target language expression cannot be guaranteed without considering the adjustment mechanism of context in translation (Liu, 2003). In summary, the concepts of context can be divided into "linguistic context" and "non-linguistic context": "Linguistic context" includes the context of written language and the context of spoken language, and "non-linguistic context" includes "situational context" and "cultural context".

Linguistic context belongs to the linguistic factors, and it is the linguistic environment existing within the language. It refers to the context of words in the process of communication. Specific translation should be tested and corrected by means of specific context.

Situational context refers to the specific situation when speech occurs, such as the time, place, occasion, and participants of speech. Situational context includes not only language, but also facial expression, posture, physical activity, all the people involved in the conversation, and their part of the environment. Situational context is very important for translation. Only by analyzing the specific situational context and analyzing the specific background information such as time, space, age, identity, and occupation can we ensure the quality of the translation. Once the situational context changes, the meaning of language may also change.

Cultural context refers to the environment of the whole linguistic system. It is the social and cultural form on which linguistic forms depend. It involves all aspects of human life. Cultural context includes such factors as social background, historical background, national and cultural background, mode of thinking, language and culture on which verbal communication activities take place. Cultural context not only influences the meaning of words and discourses, but also endows them with more meanings. Cultural context promotes the understanding of foreign vocabulary, idioms, and discourse meanings.

Translation is actually the transformation of meaning between different contexts. Successful translation requires maximizing contextual meaning between the translator and the author of the original text, as well as between the translator and the target reader (Peng, 2002, p. 60). Therefore, in the stage of comprehension and expression of translation, the translator must fully consider the influence of context on language form and meaning.

\section{Context and Translation Teaching}

Context, as a hot topic in translation teaching, has attracted the attention of many translation scholars and translation teachers. The combination of context and translation teaching is also one of the breakthroughs in the reform and innovation of translation teaching. Emphasizing the combination of context and translation teaching does not mean weakening or negating the most basic translation teaching tasks, such as the introduction of translation theory and the explanation of translation skills, but on the basis of this, perfecting the teaching mode, integrating context teaching into it, closely combining with the requirements of modern language service 
industry for translators, and gradually cultivating translators who can adapt to market demand and be competent for actual translation.

\section{Context and Selection of Translation Textbooks}

The first thing that needs to be changed in context-based teaching is the textbooks of translation course, because textbooks are the carriers of teaching content, which largely determine the teaching purpose and methods of the course. The translation class should attach importance to textbooks rather than sticking to them. Most of the translation textbooks currently used in most universities in China focus on the introduction of translation theories and the training of translation skills, such as English Chinese Translation Course, Practical Translation Course, etc. Although the number and types of translation textbooks that have been officially published are considerable, the current translation textbooks are "too many repetitions, lack of novelty" (Tao, 2006, p. 33). At present, translation teaching is often based on the knowledge system of a translation textbook and some supplementary materials.

Paying attention to textual translation materials. Contextualized teaching requires textbooks to use texts as materials for translation, because from the perspective of linguistic context, words in dictionaries are given meaning only in specific contexts. If students depend heavily on dictionaries for their choice of meanings and do not have the awareness of context, the translated version will be stiff and lose the style and meaning of the original text. Therefore, sentence-centered translation textbooks have become outdated. Fortunately, some textbook-oriented translation textbooks have been published in China, abandoning sentence-centered translation teaching mode, such as Li Yunxing's English-Chinese Text Translation.

Emphasizing authentic translation materials. Traditional translation textbooks are mainly literature, politics, and science and technology materials, which are limited in content and not closely related to language services. There is a big gap between the translation teaching in universities and the professional needs of the translator. Contextualized teaching emphasizes the authenticity of translation materials. In reality, translation involves a wide range of contents, such as politics, economy, science and technology, law, culture, etc. Considering the social demand for translators, teachers should use practical translation materials such as diplomacy, cultural exchange, business and trade in translation classes. Through school-enterprise cooperation, we can obtain the real text materials, publicity materials, product specifications, business contracts, and so on. Emphasis should be placed on the guidance of translation market to translation teaching, and the effectiveness of teaching should be based on social needs.

Attaching importance to translation practice in textbooks. Contextualized teaching also needs to take into account the context of the whole society in compiling translation textbooks: Many graduates of English majors are not qualified for translation work. One of the reasons is that many textbooks do not involve translation projects, translation companies, editors, and other practical operations of translation. In translation teaching, teachers should make up for the simplicity of a textbook through the combination of network or multi-textbooks, so that students can understand some basic contents involved in translation practice, such as translation cooperation, translation project management, and so on.

To sum up, compared with traditional translation teaching materials, contextualized translation teaching requires teachers to abandon traditional meaning-centered and sentence-centered translation textbooks, guide students to build up discourse awareness, at the same time achieve authenticity and diversification of translation textbooks, emphasize the content of translation practice, and keep pace with the times. 


\section{Context and Translation Teaching Contents}

Emphasizing cultural context. The comprehension and expression of translation are carried out in context. The context includes phrase collocation, sentence, paragraph, text, and even social culture. Translation is not only the transformation between two languages, but also the communication between two cultures. Cultural factors play an important role. The process of reconstructing the target language is largely constrained by cultural context. Contextualized teaching requires translation not only to be meticulous in terms of syntax and lexicon at the micro level, but also to grasp the social, historical, and cultural background of the original work at the macro level. In translation class, besides vocabulary and syntax, the teaching content should also include cultural context. In the process of translation teaching, after the students understand the meaning of words, sentences, and paragraphs in the context, they also need to understand the cultural information attached to the language. Students must pay attention to the specific meaning of the English equivalent in the English cultural context: For example, the translation of "Jade Rabbit" should be translated as "Moon Rabbit" instead of "Jade Rabbit". Unfortunately, even for senior students of foreign language majors, most of them still lack an understanding of the cultural context of the original text in translation.

Therefore, in the process of classroom teaching, teachers should not neglect the cross-cultural nature of translation. They should pay more attention to cultural context fundamentally, expand relevant cultural background information purposefully, and help students understand different cultural backgrounds in depth. Only by learning the culture behind translation can we learn to read the context. If students lack bilingual cultural background knowledge, they will encounter great obstacles in the practical operation of translation. In the practice of translation teaching, teachers can arrange the teaching content with "theme" as the unit, such as "diet culture", "religion culture" as the theme for the design of translation classroom. By translating different themes, students can have a deep understanding of cultural similarities and differences, pay attention to cultural background knowledge, and strengthen cultural context awareness in future translation practice.

Attaching importance to cultural context also requires teachers to pay constant attention to the continuous changes of Chinese cultural context. With the continuous improvement of China's soft power, the voice of Chinese culture going to the world is increasing. An important aspect of Chinese culture going abroad is Chinese culture's external communication. Chinese culture is widely spread, but almost all forms of communication rely on translation. The success of translation and translation directly determines the effect of Chinese culture's external communication. For example, the concept of "Qi", "Yin and Yang”, and "qigong” in Chinese medicine culture has been controversial in the field of TCM translation. Nowadays, people generally accept the English translation of these words "Qi", "Yin and Yang”, and "qigong”. It is precise because of the "globalization" and the soft power of China that the translation of these words is likely to be acceptable to the readers. Translation is not a vacuum in isolation from society. It is a task for translation teachers to focus on the context of China and the world and pay attention to the dynamics of translation and keep in line with the market.

Attaching importance to translation technology. Contextualized teaching requires translation teaching to conform to the context of the times. Under the impact of digital wave and network, the concepts of computer-aided translation, big data, cloud translation, and translation corpus are making a profound change in translation industry and translation behavior. Michael Cronin (2013), a professor of translation studies at Dublin City University, has pointed out in her book Translation in the Digital Age that "the era of translation is the era of digitalization". Translation in the new century is characterized by technicalization, and the 
development of translation technology has changed the way text is processed. Many universities in Europe and the United States have offered various courses of translation technology, while Chinese universities do not offer such courses. The research and teaching of translation technology are obviously insufficient, and students lack the knowledge of translation software. In the new era, translation technology has become a necessary skill for a qualified translator.

In order to adapt to the background of the times, translation teaching should cultivate students' ability of applying modern translation technology. Translation teachers should conform to the trend of the times and integrate modern information technology with translation teaching. They should be familiar with and master various software and translation corpus, such as Yaxin and Tados, with the help of terminology database and terminology management. From the perspective of language environment, students will lose a lot of opportunities in the face of fierce market competition without learning and mastering basic translation techniques. From the point of view of translation teachers, in translation schools in foreign countries, "most of the teachers are professional translators, who have very rich experience in translation, and receive teaching after training” (Liu, 2000, p. 44), while many translation teachers in China graduated from foreign languages and seldom enter the language service industry. If you want to let students master translation technology, you should first become an expert in this field. Translation teachers should improve their mastery of translation techniques through various ways, such as translation practice and translation training, in order to meet the requirements of translation teaching in the new era, and then guide students to use modern technology to improve their translation ability. Domestic research on artificial intelligence has also begun to pay attention to contextual problems and systematically describe contextual factors.

\section{Context Creation and Translation Teaching}

Looking at the deficiencies of translation teaching in China, one of them is the relatively simple teaching mode. Statements and explanation are the main teaching methods. There is no interaction between teachers and students, and between students and students. Teachers explain translation skills, assign translation assignments, comments on assignments, and correct errors. The new teaching mode should develop towards self-learning and personalized learning. In the new contextual teaching mode, the role of teachers should be transformed into "supervisor" and "helper", instead of playing the role of "monologue”; they should be the person who designs and presents the situation. Classroom teaching should be student-centered and arouse students' interest and enthusiasm, so as to improve their participation in the classroom. In this context, teachers can adopt a variety of teaching strategies, organize classroom activities, and bring students into specific contexts, so as to improve students' translation practice level.

Establishing "translation workshop" to create context. One of the ways to realize the real context is that teachers can set up "translation workshops". Translation workshop is a student-centered and process-oriented teaching model. In this teaching mode, teachers and students discuss a translation project. Teachers are responsible for organizing, guiding, and supervising, and students are responsible for translation practice. Teachers can divide students into several groups to prepare, search for information, discuss and complete a translation project after class. After class, each group has a team leader who is responsible for formulating translation schedule and assigning translation work. After each group member completes their translation tasks, the team leader convenes a meeting to review and revise. Teachers are ultimately responsible for collecting and grading translations. In this way, the students complete the translation in the simulated real 
context. This "translation workshop" teaching mode makes the classroom teaching more close to the real translation practice, realizes the simulation of the translation market cooperation mode, enables students to cultivate and improve their translation ability in practice, enables students to have the opportunity to imitate and experience translation practice, creates the context atmosphere, and realizes the unity of teaching and practice. Translation teachers should realize that practice is an important principle in translation teaching. The weaknesses and shortcomings of the traditional translation classroom teaching model are increasingly apparent, ignoring the students' thinking initiative, which is not conducive to the cultivation of students' translation ability in the real context. "We need to teach knowledge and skills in real situations and provide students with different situations to use these ideas instead of implanting abstract rules to make students memorize and apply them to pre-set problems" (Jonassen, Peck, \& Wilson, 2007, p. 95).

Creating context by using multimedia technology. Another effective teaching strategy is to use multimedia technology to create real situations, because multimedia technology can make the classroom lively and three-dimensional; multimedia technology can use sound, image, and other means to show different scenes and their characteristics; multimedia teaching can create three-dimensional space. Therefore, multi-media technology can be used to create situations in translation classes and put students in certain contexts to experience translation in different contexts.

How to use multimedia to set context? Multimedia courseware, as a special text, has contextual function. In translation teaching, teachers can use multimedia technology to create vivid situational context and cultural context. For example, teachers can introduce classical or popular English films, talk shows in the translation class, analyze the English expressions and subtitle translation in a specific context, or allow students to make a contrastive translation of Chinese and English expressions in a specific context, so as to enable students to feel the differences between English and Chinese translation skills and the differences between Chinese and English in context. The development of information technology is bound to bring about changes and innovations in translation teaching. It is an inevitable trend for the development of translation teaching to strive to create a student-centered and multimedia-assisted teaching model.

Establishing an experimental base and creating context. Translation skills can only be mastered through a lot of practice, so it is necessary to provide students with a real training environment. The combination of contextualization and translation teaching urges translation teaching to provide and design vivid contexts and introduce real contexts into the classroom. Establishing a translation experimental base of "integration of industry, teaching and research" is another way to innovate translation teaching mode. In the west, translation teaching attaches great importance to integrate with the market, and occupation oriented translation teaching occupies an absolute advantage in the teaching system of translation. At home, some colleges and universities have made effective attempts in this area, and initiated the collaborative work of industry, university, and research. For example, Beijing Language and Culture University has established stable cooperative relations with a number of translation companies, and a master's degree in translation project management at Peking University. Kiraly (2000), a German scholar, pointed out that "in the process of developing translator's ability, we should create real situations, use authentic translation materials, and at the same time enable trained personnel to cooperate properly so as to achieve better results”. Strengthening the cooperation between colleges and universities, enterprises and institutions can enable students to gradually understand and familiarize themselves with the process of translation through real translation projects and master the translation norms in the real context. 


\section{Conclusion}

Today, soft power has gradually become the competitive field of national comprehensive strength. Translation is playing a unique and decisive role. As an important tool for national cultural export, the strategic significance of translation has become increasingly prominent. At present, the shortage of translation talents has become the bottleneck of Chinese culture's "going global”. College students are the main force to participate in international cross-cultural exchanges in the future. Translation teachers should make full use of the advantages of contextual teaching to make translation lessons keep pace with the times, gradually adapt to market demand, pay attention to practicality, clarify the purpose of translation teaching, improve the translation ability of college students, make them better qualified for practical translation work in the future, and meet the needs of translation market for translation talents. In this way, translation will play an important role in the process of spreading Chinese culture to the world.

\section{References}

Cronin, M. (2013). Translation in the digital age. London and New York: Routledge.

Firth, J. R. (1957). Papers in Linguistics 1934-1951. Oxford: Oxford University Press.

Halliday, M. A. K. (1978). Language as social semiotic: The social interpretation of meaning. London: Arnold.

Hu, Z. L., Zhu, Y. S., \& Zhang, D. L. (1989). A survey of systemic functional grammar. Changsha: Hunan Education Publishing House.

Jonassen, D. H., Peck, K. L., \& Wilson, B. G. (2007). Learning with technology: A constructivist perspective. Beijing: Education Science Press.

Kiraly, D. A. (2000). Social constructivist approach to translator education: Empowerment from theory to practice. Manchester: St. Jerome Publishing.

Liu, H. P. (2000). On teaching translation and translation teaching again-from the translation of letters. Chinese Translators Journal, (4), 40-45.

Liu, M. Q. (2003). Translation teaching: Practice and theory. Beijing: China Translation Corporation.

Malinowski, B. (1923). The problem of meaning in primitive in languages. In C. K. Ogden and I. A. Richards (Eds.), The meaning of meaning (pp. 296-336). London: Routledge.

Peng, L. Y. (2002). A new probe into the relationship between context and translation. Foreign Language Teaching, (2), 59-62.

Tao, Y. L. (2006). The construction of English-Chinese translation textbooks in context of Skopos theory. Foreign Language World, (2), 33-40. 